InterAção | 29

\title{
O NOVO DIREITO INTERNACIONAL: APORTES RELACIONADOS AO CONSTITUCIONALISMO MULTINÍVEL DE FERRAJOLI
}

\author{
Valéria Ribas do Nascimento ${ }^{1}$ \\ 0 problema fundamental em relação aos direitos do homem, \\ não é tanto o de justificá-lo, mas o de protegê-lo. (Norberto Bobbio)
}

Resumo

O estudo do Direito na contemporaneidade é marcado principalmente por características evidenciadas no período Pós-Segunda Guerra Mundial, sendo cabível a firmar que está surgindo o que se pode denominar de novo Direito Internacional para a pessoa humana ou para a humanidade como um todo. $\mathrm{O}$ "jus gentium" busca a superação do positivismo jurídico desacreditado, reconhecendo que acima da vontade dos Estados está a consciência humana. Nesse mesmo sentido, Luigi Ferrajoli afirma que o constitucionalismo tradicional, voltado apenas à perspectiva interna comporta uma ausência de eficácia nos diversos níveis de poderes estatais levando ao

1 Doutora em Direito Público pela Universidade do Vale do Rio dos Sinos (UNISINOS), com período de pesquisa na Universidade de Sevilha; Mestre em Direito Público pela Universidade de Santa Cruz do Sul (UNISC); Graduada em Direito pela Universidade Federal de Santa Maria (UFSM); Professora Adjunta de Direito Constitucional e Direito Comunitário e da Integração da Universidade Federal de Santa Maria (UFSM); Integra 0 Grupo de Pesquisa Núcleo de Direito Informacional (NUDI-UFSM), inscrito no CNPq. Endereço para correspondência: valribas@terra.com.br. 
30 | InterAção

risco de fazer das Leis Fundamentais simples fachadas, com meras funções de "mistificación ideológica del conjunto". Justamente com o intuito de responder a esses problemas, Ferrajoli elaborou a teoria que leva o nome de "garantismo", nascida no direito penal como uma constatação ao desrespeito dos direitos humanos e fundamentais. Posteriomente, apresenta o constitucionalismo multinível, como uma prosposta voltada a necessária conexão entre o direito constitucional e o internacional. Destaca-se que não se pretende esgotar o assunto, mas sim apresentar um outro horizonte que deve ser trabalhado na perspectiva cosmopolita.

Palavras-chave: Novo Direito Internacional, consticionalismo, humanidade, direitos humanos e fundamentais.

\section{Abstract}

Contemporary law studies are mainly marked by characteristics of post-Second World War period, and it is possible to state that a new International Law has been emerging for people or for humanity as a whole. The jus gentium seeks to overcome the discredited legal positivism, and it recognizes that above the will of the States there is the human conscience. In this sense, Luigi Ferrajoli states that the traditional constitualism, that is only directed to the internal perspective, comprises an absence of efficacy in the several levels of state powers, raising the risk of taking Fundamental Laws as a mere facade with the simple role of "mistificación ideológica del conjunto". In order to reflect on this point, Ferrajoli has created a theory called 
InterAção | 31

garantism from criminal law as evidence of disrespect to human and fundamental rights. Later, he presents the multilevel constitutionalism as a proposal aimed at linking constitutional and international law. We do not intend to exhaust the subject, but to present another view to be considered in the cosmopolitan perspective.

Keywords: New International Law, constitucionalism, humanity, human and fundamental rights.

\section{INTRODUÇÃO}

Inicialmente vale salientar que para Ferrajoli, a teoria garantista pode ser percebida através de diferentes concepções, baseando-se na redefinição do modelo normativo de direito, da crítica do direito e da política (FERRAJOLI, 2000, p. 851-2). Todas essas abordagens buscam fugir do legalismo e avançar em termos democráticos. Ademais, para fugir do que ele chama de "anarquia planetária"(FERRAJOLI, 2007, p. 554), propõe uma ordem internacional baseada em um modelo federado, com determinadas alterações no conjunto atual da Organização das Nações Unidas. Busca a defesa de uma esfera pública global heterônoma, baseando-se em um aumento da descentralização de poder.

A formação de uma nova esfera pública seria pleiteada por uma democracia global, almejada pelo lado oposto àquele que foi seguido na construção da democracia constitucional dos ordenamentos nacionais. Ele defende uma refundação do direito internacional através de vínculos entre legislações que estabelecem repartições em diferentes níveis - multiníveis - de competência. Dentre os empe- 
cilhos ao constitucionalismo multinível, Ferrajoli coloca a indisponibilidade das grandes potências e dos impérios multinacionais em submeterem-se a limitações de qualquer tipo.

A dúvida que persiste ao ler a obra do autor italiano é sobre o progressivo "constitucionalismo muttilivello senza Stato" (FERRAJOLI, 2007, p. 558). Não existe empecilho sobre a correta exposição do autor no tocante à construção de uma esfera pública global e ao reconhecimento do pluralismo dos ordenamentos. Entretanto, mostra-se complicado concordar com a teoria de um constitucionalismo sem Estado. O papel do Estado é importante ao constitucionalismo, mesmo que seja em níveis diferenciados, como quer Ferrajoli. Quiçá, o desafio seja identificar qual o nível e o comprometimento de cada Estado neste processo.

\section{0 garantismo e 0 constitucionalismo}

A teoria garantista apresenta três acepções diversas, mas relacionadas entre si: "modelo normativo de direito; teoria do direito e crítica do direito; filosofia do direito e crítica da política”. Segundo a primeira, o garantismo designa um modelo normativo do direito, precisamente porque ligado ao direito penal, no que toca a estrita legalidade, princípio basilar do Estado de Direito que, no plano epistemológico, se caracteriza como um sistema cognoscitivo ou de poder mínimo; no plano político, como uma técnica de tutela capaz de minimizar a violência e maximizar a liberdade; no plano jurídico como um sistema de vínculos impostos à vontade punitiva do Estado em garantia dos direitos dos cidadãos. "En consecuencia, es garantista 
todo sistema penal que se ajusta normativamente a tal modelo y lo satisface de manera efectiva" (FERRAJOLI, 2007, p. 851-2).

Mas, essa acepção, apontada por Ferrajoli, deve ser observada a partir de graus, ou seja, segundo ele "al tratarse de um modelo límite, será preciso hablar, más que de sistemas de garantistas o antigarantistas tout court, de grados de garantismo (...)"(FERRAJOLI, 2007, p. 851-2). Isso quer dizer que, se os princípios constitucionais são efetivamente implementados, existe um grau alto de garantismo, enquanto que, se não são respeitados, ocorre um baixíssimo grau de garantismo. Alem disso, pode-se medir a bondade de um sistema constitucional mediante os mecanismos de invalidação e reparação idôneos para assegurar a normatividade dos mencionados direitos. Daí que é mencionada uma máxima: "una Constitución puede ser avanzadísima por los principios y los derechos que sanciona y, sin embargo, no pasar de ser un pedazo de papel se carece de técnicas coercitivas (...)"(FERRAJOLI, 2007, p. 852). Isso significa a necessidade de garantias que permitam o controle e a neutralidade das funções estatais em busca de um direito legítimo. Em outro sentido, o grau de garantismo é medido pelo grau de efetividade das normas constitucionais.

A segunda acepção que trata da teoria e crítica do direito designa uma teoria jurídica da validade e da efetividade como categorias distintas não somente entre si, mas também com relação à existência ou vigência das normas. Nessa linha de orientação, a palavra garantismo expressa uma aproximação teórica que mantém separados o ser e o dever ser no direito, incluindo uma questão teórica central, baseada na divergência existente nos ordenamentos complexos entre modelos normativos e práticas operativas (FERRAJOLI, 2000, p. 851). 
Sergio Cademartori refere que, nesta segunda abordagem, garantismo direciona-se às teorias da validade, da efetividade e da vigência normativa, compreendidas como diferentes entre si. Isto é que permite a percepção da diferença entre "ser e dever-ser" no direito, verificando-se a dissonância existente entre os modelos normativos (tendencialmente garantistas) e as práticas efetivas (tendencialmente antigarantistas) como seu problema central. Quanto aos primeiros, pode-se dizer que são válidos, mas ineficazes e, quanto às práticas, são inválidas, porém eficazes. Assim, Ferrajoli apresenta redefinições dos conceitos tradicionais de vigência, validade, legitimidade e eficácia (CADEMARTORI, 2006, p. 97-8).

É sabido que existem diferentes conceitos para vigência, validade e eficácia, mas, para muitos dos mais reputados autores, a noção de validade corresponde à noção simplista de existência jurídica, ou seja, é fruto de um procedimento previsto em norma superior (KELSEN, 1998; HART, 2007; BOBBIO, 2003). Porém, esse critério não leva em consideração o fato de que o Estado Constitucional incorpora princípios étíco-políticos que exigem uma redefinição com base em critérios de legitimidade internos. Assim, o garantismo estabelece uma importante distinção entre quatro predicados que podem se imputar às normas: justiça, vigência, validade e eficácia (efetividade):

a) uma norma é justa quando responde positivamente a determinado critério de valoração ético-político (logo, extrajurídico);

b) uma norma é vigente quando é despida de vícios formais; ou seja, foi emanada ou promulgada pelo sujeito ou órgão competente, de acordo com o procedimento prescrito; 
InterAção | 35

c) uma norma é válida quando está imunizada contra vícios materiais; ou seja, não está em contradição com nenhuma norma hierarquicamente superior;

d) uma norma é eficaz quando é de fato observada pelos seus destinatários (e/ou aplicada pelos órgãos de aplicação) (CADEMARTORI, 2006, p. 101-2).

Segundo Cademartori, a relevância dessa distinção está no fato de que as qualidades apresentadas são totalmente dissociadas entre si, sendo a finalidade da distinção justamente salientar a diferença entre vigência e validade. "Por exemplo, uma norma pode ser justa e no entanto não observada (não eficaz) e vice-versa, uma norma pode ser observada embora injusta". Para Ferrajoli, ainda pode acontecer que "uma norma seja vigente e eficaz mesmo sendo inválida, como pode acontecer que uma norma seja válida mas nem por isso eficaz" (CADEMARTORI, 2006, p. 102).

Já a terceira acepção se liga à filosofia do direito e da política. Logo, o garantismo designa uma filosofia política que desperta no direito uma carga de justificação externa conforme os bens e interesses cuja tutela e garantia constitui precisamente a finalidade de ambos. Com efeito, neste último sentido o garantismo pressupõe a doutrina laica da separação entre direito e moral, entre validade e justiça, entre um ponto de vista interno e outro externo, quer dizer, entre ser e dever ser (FERRAJOLI, 2000, p. 853).

Pelo que foi exposto, é possível verificar que Ferrajoli não nega um certo viés positivista, denominado-se como positivista crítico. Essa posição é diversa daquela concebida por Gustavo Zagrebelsky, que nega a contribuição iluminista ao movimento que hoje se 
36 | InterAção

denomina neoconstitucionalismo (ZAGREBELSKY, 2007)2.

Ao contrário, o garantismo de Ferrojoli caracteriza-se por ser uma crítica do direito positivo vigente, não meramente no panorama externo, mas também no interno, posto que ataca aspectos relacionados à efetividade e à validade. Como afirma o próprio autor:

Este planteamiento, que bien podemos llamar positivismo crítico, se refleja en el modo de concebir el trabajo del juez e del jurista, y pone en cuestión dos dogmas del positivismo dogmático: la fidelidad del juez a la ley y la función meramente descriptiva y avalorativa del jurista en relación con el derecho positivo vigente (FERRAJOLI, 2000, p. 872).

A partir das reflexões apontadas, a estrutura garantista consiste em incluir valores como limites ou deveres em níveis mais altos do ordenamento constitucional, com a finalidade de limitar os demais poderes do Estado. Mas, uma vez incorporados aos níveis mais altos,

2 Miguel Carbonell acredita que existem três distintos níveis a serem analisados ao tratar de neoconstitucionalismo. Dentre eles está a época histórica, pois este novo movimento constitucional pretende explicar um conjunto de textos constitucionais que surgem depois da Segunda Guerra Mundial, mais particularmente a partir dos anos setenta do século XX. Em segundo lugar, estão as práticas jurisprudenciais, que exigem dos juízes novos parâmetros interpretativos. Aqui, entram em jogo técnicas hermenêuticas apoiadas em princípios constitucionais e em diferentes teorias, como a da ponderação, a da proporcionalidade, a da razoabilidade, a da maximização dos efeitos normativos dos direitos fundamentais, dentre outras. 0 terceiro e último nível está ligado a novos desenvolvimentos teóricos, que partem do sentido material de textos constitucionais para tentar explicar os fenômenos jurídicos. Podem-se citar várias doutrinas, como por exemplo, a de Ronand Dworkin, Robert Alexy, Gustavo Zagrebelky, Luigi Ferrajoli, Carlos Nino e Luis Prieto Sanchís (CARBONELL, 2007). 
InterAção | 37

os valores são confiados aos órgãos judiciais para apreciação.

De fato, o poder de disposição através de valorações livres, que no Estado Absoluto era admitido desde baixo pelos fatos, no Estado de Direito encontra-se excluído desde baixo, mas deve ser admitido a partir de cima. "En todos casos, con los valores no caben exorcismos: si se expulsan por la puerta, entran de nuevo por la ventana. Y en el fondo está bien que así sea"( FERRAJOLI, 2000, p. 872). Ferrajoli quer dizer que estas aporias do garantismo não têm nada de supreendentes; apenas exigem que se criem distâncias entre as promessas normativas e as práticas efetivas do ordenamento.

Essa reinterpretação do contratualismo clássico, funciona como um esquema de justificação do Estado, enquanto instrumento de tutela dos direitos fundamentais. Nesse sentido, para Ferrajoli, as diversas crises pelas quais passa o Estado, como por exemplo a crise do princípio da legalidade, da estrutura do Estado de Bem-Estar Social e do próprio Estado Nacional, não podem dar margem a nenhum tipo de descodificação, deslegislação ou de desregulamentação, mas, ao contrário, deve ocorrer uma aproximação do direito ao concreto funcionamento das instituições jurídicas. Por isso, o direito relaciona-se com uma realidade - não natural, mas artificial - construída através dos homens, os quais têm responsabilidade com a humanidade. A alteração em diversos planos do modelo positivista clássico, proposta por Ferrajoli, além de abarcar a teoria do direito, em que propõe uma revisão aos planos da existência, validade e eficácia, como foi ora demonstrado, alcança também o plano da teoria política, em que há uma revisão da concepção puramente procedimental da democracia e o reconhecimento da dimensão substancial. 
38 | InterAção

Para Daniela Mesquita Leutchuk de Cademartori e Sergio Cademartori quando se trata da relação entre Estado de Direito e Democracia deve-se ter sempre presente a associação realizada por Norberto Bobbio e Luigi Ferrajoli, sendo que a natureza de tal vínculo diz respeito ao alcance do conceito de democracia. Bobbio considera que é preciso não confundir Estado de Direito e democracia. Em que pese um juízo a respeito da segunda, dever sempre considerar a existência ou não da primeira. Para Ferrajoli, que trabalha a partir das noções de Bobbio, ocorre a ampliação do conceito de Estado de Direito cruzando todos os poderes à tutela substancial de direitos: "o Estado de direito não surge só historicamente antes do democrático (...), mais do que isto, este Estado é axiologicamente anterior ao Estado democrático" (CADEMARTORI; CADEMARTORI, 2006, p. 145). Na verdade, os juristas brasileiros estão chamando a atenção para o aspecto substancial da democracia, defendido por Ferrajoli.

Se comprende (...) que una tal dimensión substancial del Estado de derecho se traduce en dimensión sustancial de la propria democracia. En efecto, los derechos fundamentales constituyen la base da la moderna igualdad, que es precisamente una igualdad en droits, en cuanto hacen visibles dos características estructurales que los diferencian de todos los demás derechos, a empezar por el de propiedad: sobre todo su universalidad, es decir, el hecho de que corresponden a todos y en la mesma medida, al contrario de lo que sucede con los derechos patrimoniales, que son derechos excludendi alios, de los que un sujeto puede ser o no titular y de los que cada uno es titular con exclusión de los demás; en segundo lugar, su naturaleza de indisponibles e inalienables, tanto activa como pasiva, que los sustrae al mercado y a la decisión política, 
InterAção | 39

limitando la esfera de lo decidible de uno y otra y vinculándola a su tutela y satisfacción (FERRAJOLI, 2006, p. 23).

Dessa forma, a constitucionalização dos direitos fundamentais serve para injetar uma dimensão não apenas formal, mas substancial no próprio direito - como ciência social - e na democracia. Ferrajoli traz algumas redefinições para soberania popular: "una ridefinizione della sovranità popolare: a) come garanzia negativa; b) come somma dei diritti fondamentali" (FERRAJOLI, 2007, p. 9). É patente a superação da democracia apenas em sua perspectiva representativa pelo voto nas urnas; assim, mesmo referindo o primeiro significado como representativo da democracia política, surge o segundo significado compatível com o paradigma democrático constitucional que está associado ao direitos fundamentais. Para Ferrajoli:

(...) La formula la sovranità appartiene al popolo vuele quinde dire, cioè di tutte le persone di cui il popolo si compone: appartiene, in brevi, a tutti e a ciascun cittadino, in quanto equivale alla somma di quei poteri e contro-poteri di tutti - i diritti politici, i diritti civili, i idiritti de libertà e i diritti sociali che sono i diritti fondamentali constitucionalmente stabiliti (...) (FERRAJOLI, 2007, p. 9).

Esses direitos fundamentais não estão total disposição dos cidadãos, mas justamente devem ser analisados no caso concreto. E, precisamente, porque estão previstos na Constituição, podem ser usados também pelo mercado e pela política, formando "la 'esfera de lo indecidible que' y de lo 'indecidible que no"; atuando como fatores não somente de legitimação, mas também e, sobretudo, como fato- 
40 | InterAção

res de deslegitimação das decisões e das não decisões (FERRAJOLI, 2006, p. 24). Aqui entra, novamente, a discussão em torno do papel dos juízes e da sua legitimação democrática.

Para Ferrajoli, atualmente, a sujeição do juiz à lei já não é como no Estado Legislativo, baseado no velho paradigma positivista. Ao contrário, a jurisdição constitucional deve ser pautada pela lei válida ou coerente com a Constituição. Ademais, esta legitimação do Poder Judiciário não tem nada a ver com a democracia política, ligada à representação. "No deriva da la voluntad de la mayoría, de la que asimismo la ley es expresión". O fundamento é unicamente a intangibilidade dos direitos fundamentais (FERRAJOLI, 2006, p. 27). Essa pertinente colocação quer dizer que a legitimação democrática dos juízes deriva da própria função de garantidor dos direitos fundamentais, em que se baseia a ideia de democracia substancial.

Nessa linha de orientação, os princípios da igualdade e da legalidade se unem - "como la otra faz de la misma medalla con el segundo fundamento político de la independencia del juez: su función de averiguación de la verdad procesal, según las garantías del justo proceso."(FERRAJOLI, 2006, p. 27).

Há que se concordar com o autor quando se refere ao importante papel dos juízes nas democracias constitucionais contemporâneas, principalmente nos países "em via de desenvolvimento", em que o processo político eleitoral é muitas vezes dominado por fatores econômicos e pela mídia, nem sempre neutra e imparcial. Observa-se que Ferrajoli, mesmo estando inserido em um contexto cultural diferenciado, em um continente já em franco processo de integração, critica as doutrinas procedimentalistas e consensualistas. 
InterAção | 41

Veja-se longa transcrição da obra:

Aquí, de nuevo, no juega el principio de mayoría. Es más, no sólo resulta extraño, sino que está en contradicción con el fundamento específico de la legitimación del poder judicial. Ninguna mayoría puede hacer verdadero lo que es falso, o falso lo que es verdadero, ni por tanto, legitimar con su consenso una condena infundada por haber sido decidida sin pruebas. Por eso me parecen inaceptables y peligrosas para las garantías del justo proceso y, sobre todo, del proceso penal las doctrinas consensualistas y discursivas de la verdad que - nacidas en el contexto de disciplinas muy diferentes, como la filosofía de las ciencias naturales (Kuhn), o la filosofía moral o política (Habermas) - algunos penalistas y procesalitas querrían importar ahora en el proceso penal, quizá para justificación de esas instituciones aberrantes que son las negociaciones sobre la pena. En efecto, ningún consenso - ni el de la mayoría, ni el del imputado - puede valer como criterio de formación de la prueba. Las garantías de los derechos no son derogables ni disponibles. Aquí, en el proceso penal, no valen otros criterios que los ofrecidos por la lógica de la inducción: la pluralidad o no de las pruebas o confirmaciones, la ausencia o presencia de contrapruebas, la refutación o no de las hipótesis a la de la acusación (FERRAJOLI, 2006, p. 27-28).

É necessário deixar claro que as divergências entre as posturas substancialistas (que abrangem as questões de Estado voltadas aos conteúdos materiais da Constituição, atentando à mudança no "status quo" da sociedade, defendendo o papel da justiça constitucional na efetivação dos direitos fundamentais) e procedimentalistas (que acoplam a noção de democracia procedimental, baseada em Habermas e no ideal do consenso) não devem ser entendidas como oposições 
42 | InterAção

radicais, a ponto de se pensar que o substancialismo não é pluralista ou que o procedimentalismo é baseado em formalismos. "Também não se pode pensar que uma é democrática, e a outra não, ou que os procedimentalistas não estão preocupados com a concretização dos direitos fundamentais e com a preservação da Constituição". Na verdade, como Streck argumenta, os caminhos é que são diferentes, porque calcados em paradigmas filosóficos distintos (STRECK, 2009, p. 35-36).

Partindo dessa postura substancialista, Ferrajoli, igualmente, refere que o modelo garantista está sendo continuamente atacado; primeiro, pela própria incoerência e falta de plenitude gerada pelas constantes violações a direitos fundamentais; segundo porque o Estado Democrático de Direito, não consegue dar conta das demandas por direitos sociais, difusos e coletivos; e por último, pela alteração no sistema de fontes do direito, já que existe o ingresso de legislações internacionais nos ordenamentos internos (FERRAJOLI, 2006, p. 30). Pelo exposto, percebe-se que estão ocorrendo importantes alterações na estrutura do constitucionalismo que está na base da função mesma do direito, como sistema de garantias (FERRAJOLI, 2002, p. 53). Por isso, é urgente que a cultura jurídica avance, para um processo de integração internacional, mas com a devida atenção aos pilares constitucionais.

\section{Por um Constitucionalismo de direito internacional ou por um direito internacional voltado ao constitucionalismo?}

É sabido que o paradigma constitucional nasceu e permaneceu, até o momento, atrelado à forma do Estado Moderno. No 
InterAção | 43

entanto, segundo Ferrajoli, esta ligação entre Estados, Constituição e garantia de proteção aos direitos fundamentais é totalmente contingente e não reflete nenhuma necessidade teórica (FERRAJOLI, 2002, p. 53).

Naturalmente, como já foi mencionado neste trabalho, a globalização acarretou a urgência de se pensar novos padrões para enfrentar as diferentes crises pelas quais passa o Estado e o constitucionalismo. Nessa perspectiva, Ventura expressa que, atualmente, existe uma "caixa de ressonância de eventos no plano global". Sabe-se que os governos condicionam-se mutuamente pelas organizações internacionais e, além disso, pela atuação das corporações transnacionais. Da mesma forma, os indivíduos reagem a fatos e gestos, devido à facilitação da comunicação pelos meios tecnológicos, principalmente à internet. Os movimentos sociais participam em redes cada vez mais amplas. Assim, o papel do direito internacional atua justamente na busca por uma passagem da "opinião pública" para a "esfera pública”, ou seja, na produção de uma tecnologia jurídica capaz de dotar de maior legitimidade o processo de tomada de decisões na esfera mundial (VENTURA, 2009, p. 18; VENTURA, 2003; VENTURA, 2008,. p. 223-240.

Da mesma forma, Ferrajoli expõe certos motivos para se desenvolver um constitucionalismo de direito internacional, já que, para ele, as crises do Estado podem ser superadas em sentido progressivo, com uma despotencialização e deslocamento para o plano internacional das bases do constitucionalismo: "não apenas as sedes da enunciação dos princípios, como já aconteceu com a Carta da ONU e com as Declarações e Convenções sobre direitos humanos, mas também de 
suas garantias concretas." (FERRAJOLI, 2002, p. 53).

Para corroborar suas afirmações, Ferrajoli coloca alguns argumentos de Francisco de Vitoria, como a hipótese do "totus orbis" (mundo inteiro) - a humanidade, no lugar dos Estados, como referencial unificador do direito. Para o jusfilósofo contemporâneo esta possibilidade hoje pode ser realizada por meio da elaboração de um constitucionalismo mundial, apto a oferecer a tutela das várias Cartas de direitos fundamentais. Estes documentos devem ser levados a sério como cultura jurídica e política, cuja garantia deve ser feita pela ONU e pelos Estados que dela fazem parte (FERRAJOLI, 2002, p. 54). É interessante pontuar que Ferrajoli destaca a necessidade de despotencialização dos Estados para que o direito internacional se fortifique. A questão que se apresenta é se não seria vantagem, em curto prazo, a fortificação dos Estados e o desenvolvimento do direito internacional sob o viés neoconstitucional, ou seja, atentando pela primazia dos direitos e das garantias substanciais inseridas nas próprias Constituições estatais.

Ferrajoli reitera que não se está pensando de forma alguma num improvável governo mundial. Mas, simplesmente, imagina-se a perspectiva indicada há mais de cinquenta anos por Kelsen, em seu livro "La paz por medio del derecho", no qual se desenvolveu uma limitação efetiva da soberania dos Estados através dos instrumentos de garantias jurisdicionais contra violações à paz e aos direitos humanos ou fundamentais (FERRAJOLI, 2002, p. 53).

Segundo as bases kantianas, Ferrajoli defende a antinomia entre o direito e a guerra, chegando a dizer que há uma contradição de bases terminológicas: 
InterAção | 45

(...) La guerra può essere giustificata com ragioni extra-giuriche, di tipo economico, o politico o perfino morale. Ma non può mai essere qualificata legale, per la contraddizione che non lo consente tra diritto e guerra. Il diritto, infatti, è regolazione dell'uso della forza, laddove la guerra - al pari della criminalità omicida e di ogni altra form di violenza selaggia - è violenza sregolata. Per questo, poiché la sola foza qui potulata come permessa dal diritto è quella sottoposta a regole, la guerra, in quanto uso sregolato della forza, è, all interno di qualsiasi ordinamento giuridico, vietata (FERRAJOLI, 2007, p. 499).

Assim, o direito é um instrumento de busca pela paz, isto é, deve ser uma técnica para solução pacífica das controvérsias. Porém, obviamente que ainda existe um longo caminho pela frente para que essa paz se efetive.

Vale observar a seguinte citação de Vitoria: "sendo uma república parte do mundo inteiro..., acredito que, se a guerra for útil a uma só província ou república, mas danosa para o mundo ou para a cristandade, por isso mesmo tal guerra é injusta" (FERRAJOLI, 2002, p. 56).

Ferrajoli sublinha quatro sugestões pontuais, começando por uma reforma da Corte Internacional de Justiça de Haia, atualmente, com uma atuação de pouquíssima relevância. Dentre as propostas estão: a) aumento de competência que gira apenas em torno das controvérsias entre Estados, sendo que a extensão deve abarcar também os julgamentos de responsabilidade em matéria de guerras, ameaças à paz e violações dos direitos fundamentais; b) obrigatoriedade da sua jurisdição, hoje ainda subordinada à aceitação preventiva dos Estados; c) reconhecimento, também, aos cidadãos da capacidade postulatória perante a Corte; d) introdução da possibilidade de responsabilização 
46 | InterAção

pessoal dos governantes por crimes de direito internacional (FERRAJOLI, 2002, p. 56).

Cita, ainda, a necessidade de um paulatino desarmamento dos Estados e a proibição de armas como bens lícitos. Indica outra afirmação de Vitoria sobre os direitos dos povos, que no passado foram enunciados em benefício dos conquistadores e que deveriam hoje ser reconhecidos como forma de ressarcimento dos povoados aborígines depredados no passado. Registra-se a citação do doutrinador italiano:

o ius migrandi para nossos países ricos e de neles adquirir cidadania por força do simples título, proclamado por Vitoria, de todos nós sermos homens, e ergo videtur quod amicitia inter homines sit de iure naturali, et contra naturam est vitare consortium hominum innoxiorum (é, portanto, evidente que a amizade dos homens faz parte do direito natual, e que é contra a natureza evitar o consórcio dos homens probos) (FERRAJOLI, 2002, p. 57).

É possível verificar uma fina ironia no texto de Ferrajoli, ao relatar que os direitos naturais, em que foram baseados os direitos humanos das primeiras declarações dos Estados Modernos, eram reconhecidos a todos os seres humanos (com exceção dos direitos políticos). Naquele tempo, em que foram prometidos a todos, não se imaginava que os homens e mulheres do Terceiro Mundo pudessem chegar à Europa e pedir para serem levados a sério em nome da reciprocidade (FERRAJOLI, 2002, p. 57). Hoje, depois de terem se aproveitado dos benefícios, é difícil aos Estados revisitarem seus conceitos para, a partir deles, exercer a tolerância e a aceitação do outro e do diferente, 
InterAção | 47

simplesmente por pertencer à espécie humana. Está completamente correto Ferrajoli quando afirma a urgência de reconhecer o caráter supra-estatal dos direitos humanos e garanti-los não apenas dentro, mas também fora e contra os Estados, mas isso não retira a importância do constitucionalismo interno desenvolvido por cada país.

Nesse sentido, merece destaque a dimensão normativa da ciência jurídica. Ferrajoli diz-se positivista crítico, porque, mesmo reprovando o racionalismo iluminista não desconsidera os benefícios da razão. Até, por esse motivo, ressalta que, graças à manutenção da racionalidade nas formas de direito internacional positivo, já se tem, em outras palavras, "uma Constituição embrionária no mundo" (FERRAJOLI, 2002, p. 60-1). O que isso quer dizer? Significa simplesmente que os valores cosmopolitas como proibição à guerra, direitos dos homens e dos povos, que inicialmente surgiram ligados aos valores burgueses, formais, do Estado Moderno, depois da Segunda Guerra Mundial adquirem nova conotação, impondo-se como horizonte axiológico e deontológico nas Constituições contemporâneas.

É mais fácil a procura pelo relacionamento harmônico entre o direito internacional e o direito constitucional com vistas à efetividade e ao fortalecimento dos instrumentos internos de proteção aos direitos fundamentais, do que a busca por um novo Leviatã internacional.

\section{Apontamentos sobre 0 constitucionalismo multinivel correlato ao cosmpolitismo policêntrico e considerações finais}

Contra a ideia de um globalismo jurídico unicêntrico, Ferrajoli propõe um cosmopolitismo jurídico policêntrico e pluralístico, 
48 | InterAção

baseado principalmente nas distinções entre as funções governo e a legitimidade de representação política, asseguradas sobretudo através das instituições estatais, infraestatais e supraestatais. Ele afirma que esse é um modelo bem distante da atual estrutura da ONU, que corresponde, na verdade, a um frágil modelo confederado (FERRAJOLI, 2007, p. 553). Percebe-se que a proposta apresentada não é apenas uma referência utópica, já que a correspondência com a realidade está exposta em seu texto:

(...) Oggi, di fato, le funzioni di governo mondiale sono detenute ed exercitate soprattutto da un governo locale, quello della superpatenza statunitense; laddove le funzione di garantizia - ove riguardino aggressioni globali a diritti e beni fondamentali come la pace, la sicurezza, la sussistenza e la salvaguardia del l'ambiente - sono di fatto impossibili a livello locale e sono d'altro canto prive, a livello internazionale, delle corrispondenti instituzioni di garanzia (FERRAJOLI, 2007, p. 553).

Com isso, é factível a aplicação de sua teoria. Vive-se um período em que algumas superpotências, como os Estados Unidos, exercem um poder muito grande sobre o restante dos países, o que leva a agressões globais de diferentes dimensões, sem a correspondente proteção internacional. Até mesmo a ONU apresenta, em determinados momentos, posições parciais, tendo em vista os interesses, mesmo que de forma indireta, dos Estados que formam o Conselho de Segurança.

Assim, ocorre que os Estados e a própria sociedade deparam-se com um tipo de "anarquia planetária". Mas como enfrentar o dilemas que envolvem o embate entre diferentes espécies de Leviatãs? 
InterAção | 49

Ferrajoli apresenta uma alternativa a essa regressão da ordem internacional à guerra global infinita, que seria a transformação gradual do modelo confederado ao modelo federado (FERRAJOLI, 2007, p. 553). Tratar-se-ia de uma necessidade jurídica de fechar as lacunas que existem quanto à proteção dos direitos e garantias fundamentais:

(...) Si tratta di um obbligo non solo universale (omniu) in capo a tutti gli Stati e alle Nazioni Unite, ma anche assoluto (erga omnes), dato che vincola gli Stati non solo nei confronti dei loro popoli e dei loro cittadini, ma di tutti popoli e di tutti gli esseri umani del mondo: di un principio, quindi, di solidarietà insieme attiva e passiva, consistente nei doveri assoluti de garanzia cui sono tenuti i primi, correlativamente ai diritti universali di cui sono titulari i secondi (...) (FERRAJOLI, 2007, p. 553).

$\mathrm{Na}$ defesa do universalismo dos direitos humanos ou fundamentais e na busca pela paz, devem atuar tanto os constitucionalistas como os internacionalistas. Por isso, a sugestão é que se reconstrua uma "esfera pública global", onde o sentido do público seja diverso do atual, para efetivação desses direitos, já que isso dificilmente iniciará pela esfera privada, onde opera mais fortemente a economia. Para Ferrajoli: "la esfera pubbica è infatti una esfera eteronoma, e può essere prodotta solo dalla politica e dalla sua capacità di regolare e governare l'economia invertendo l'attuale suditanza della prima alla seconda" (FERRAJOLI, 2007, p. 555).

Hoje, a esfera pública edificada sobre os tradicionais Estados e depois sobre as instituições internacionais e supranacionais consiste numa rede intrincada e confusa, que edifica um "labirinto" formado 
50 | InterAção

por sucessivas acumulações e estratificações. Essa desagregação é percebida, igualmente, na falência da estrutura hierárquica e piramidal em que se baseavam os Estados. A antiga estrutura é substituída por um desenho fragmentado, desorganizado e heterogêneo de organizações públicas e parapúblicas, supra, inter ou transnacionais, caracterizadas de forma puntiforme e reticular e, obviamente, incapazes de dar conta de um sistema econômico e social desterritorializado, composto, ainda, por muitas empresas multinacionais (FERRAJOLI, 2007, p. 553).

Há que se concordar com o autor quando afirma que a atual globalização configura-se pela regressão às formas pré-modernas:

\begin{abstract}
Il pluralismo degli ordinamenti, la loro concorrenza, la confusione e l'anarchia delle fonti che caratteizzano l'attuale assetto dei rapperti tra Stati, istituzioni sovranazionali e insituzioni internazionali ricordano gli analoghi fenomeni che caratterizzarono i sistiemi giuridici premoderni, parimenti contrassegnati dalla convivenza in un medesimo territorio e dalla soggezione delle medesime persone a più ordinamenti: la Chiesa, l'Impero, i principati, le municipalità, le corporazioni e simili (FERRAJOLI, 2007, p. 556).
\end{abstract}

Como foi possível verificar, existe um infindável número de forças concorrentes, o que leva à descentralização de poder como acontecia na Idade Média. A diferença é que, hoje, a ordem internacional dispõe do que Ferrajoli denomina de Constituições embrionárias - a Carta da ONU e as diversas Cartas de direitos -, que evidenciam normativamente o paradigma de um constitucionalismo global (FERRAJOLI, 2007, p. 556). A formação de uma nova esfera pública 
InterAção | 51

e de uma democracia global deve ser buscada pelo lado oposto àquele que foi seguido na construção da democracia constitucional dos ordenamentos nacionais. Não se deve observar o Estado Constitucional sob o prisma Estado Legislativo de Direito, mas sim pleitear a refundação do direito internacional através de vínculos entre legislações que estabelecem repartições em diferentes níveis - multinível - de fontes de competência. Ademais, deve-se buscar a separação entre instituições de governo e instituições de garantia; bem como a necessária reabilitação do princípio da legalidade como limite e vínculo a todos os poderes, sejam públicos ou privados (FERRAJOLI, 2007, p. 556). Obviamente, que esse projeto universalístico apresenta enormes dificuldades jurídicas, políticas, sociais e culturais.

Dentre os obstáculos ao constitucionalismo multinível, Ferrajoli cita a indisponibilidade das grandes potências e dos grandes impérios multinacionais em submeterem-se a limitações de qualquer tipo. Por outro lado, sobre o plano teórico, refere que o principal problema é o da correspondência entre a natureza dos dilemas e os níveis de competência para solucioná-los em seus diversos planos de atuação. É claro que os assuntos ligados à paz, ao desarmamento e à proteção do equilíbrio ecológico do planeta, bem como à implementação dos direitos sociais, são questões de nível global, o que leva à exigência de instrumentos de proteção globais, mas também locais (FERRAJOLI, 2007, p. 556-7). Pelo que foi exposto até o momento, é verificável que Ferrajoli mantém as atribuições do Estado como sendo de fundamental importância para o desenvolvimento do constitucionalismo multinível.

Nesse sentido, conforme redação literal da obra do referido autor: 
La costruzione di uma sfera pubblica globale secondo el paradigma federale costringe percià a ripensare sia lo Stato che l'ordine internazionale. Essa non implica affatto uma riduzione del ruolo garantista degli Estati, ma al contrario la sua integrazione ai livelli sovrastatali, ove quel ruolo sia negato o violato o impedito o indebolito dagli odieni processi di globalizzazione (FERRAJOLI, 2007, p. 557).

Ferrajoli não está flexibilizando a teoria garantista, já que mantém a importância dos Estados como agentes fundamentais na implementação dos direitos fundamentais, apenas refere que, se não o fizeram, poderão ocorrer intervenções supranacionais.

Em suma, o declínio da antiga soberania estatal é "un colollario di qualunque ordinamento internazionale, tanto più se modellato nelle forme garantiste della democrazia constituzionale". Isto significa que é preciso a refundação interna das democracias ocidentais, assim como a fundação de uma democracia da ordem internacional. Aqui está a chave da ideia de Ferrajoli, ou seja, é importante uma refundação que comporte um aumento da esfera pública, através de múltiplas combinações - "di sussidiarietà, di divisione, di separazione" - e através de diversos níveis de instituições, buscando o alargamento do direito internacional ao paradigma da democracia constitucional (FERRAJOLI, 2007, p. 557)³. Não existe dúvida sobre a correta ex-

3 Sob a mesma perspectiva, ou seja, da busca por uma aproximação do Direito constitucional ao Direito Internacional, caminha a teoria da interconstitucionalida desenvolvida por Joaquim José Gomes Canotilho. (CANOTILHO, 2006). 
InterAção | 53

posição do autor de que a construção de uma esfera pública global supõe o reconhecimento do pluralismo dos ordenamentos. Por isso, é difícil concordar com a teoria de um constitucionalismo sem Estado, o papel do Estado sempre existirá no constitucionalismo, mesmo que seja em diferentes níveis, como quer Ferrrajoli.

Mesmo não concordando com a terminologia "constitucionalismo sem Estado", expõem-se os cinco elementos, apresentados pelo doutrinador italiano, para estruturação desta proposta: o primeiro é que deve existir um espaço autônomo, reservado à Constituição; o segundo, derivado do primeiro, se refere aos direitos fundamentais, de caráter individual ou social, bem como o princípio em defesa da paz, que deve possuir caráter universal; o terceiro é a manutenção dos princípios da legalidade e de submissão ao direito; o quarto elemento conexo com os outros três, relaciona-se ao funcionamento de governo, atentando, para importância da efetivação das garantias; já o quinto elemento liga-se ao modelo federado.

Essa articulação busca a perspectiva multinível da esfera pública e dos poderes, a qual vai acrescentar à tradicional separação horizontal entre funções de governo e funções de garantia a divisão e/ ou a separação vertical entre níveis federais e estatais (FERRAJOLI, 2007, p. 560). Com a multiplicação dos centros de poder, Ferrajoli pretende lançar um antídoto para a involução monocrática da democracia em nível nacional e internacional.

Ainda, vale mencionar outras duas condições inseridas na referida obra "Principia iuris", que são necessárias para o desenvolvimento do paradigma federalista transferido para as relações internacionais. A primeira é que não se deve imaginar a mesma estrutura estadista 
54 | InterAção

própria do Estado federal, já que este é apenas uma variante do velho Estado nacional soberano. $\mathrm{O}$ novo modelo se caracteriza por uma rede de relações entre ordenamentos federados, o qual possui um grau de divisão e separação de poder em diferentes níveis. A segunda condição está na base social da federação (FERRAJOLI, 2007, p. 561-2).

Pelo que foi exposto, constata-se que o complicado modelo proposto por Ferrajoli está, realmente, inserido na complexa sociedade atual, em que o tempo já não é mais o mesmo da Antiguidade, da Idade Média e da Modernidade, para usar a terminologia histórica comumente utilizada. Certamente, é uma proposta profícua e que renderá muitos desdobramentos. A crítica que se faz é sobre a posição do ente estatal neste contexto, já que Ferrajoli não quer flexibilizar o garantismo, mas, ao mesmo tempo, menciona a possibilidade de um constitucionalismo sem Estado. Particularmente, quiçá em curto prazo o mais plausível seja a recuperação do Estado como pressuposto para o próprio desenvolvimento de um constitucionalismo sob o viés cosmopolita.

\section{REFERÊNCIAS}

BOBBIO, Norberto. Estado, Governo e Sociedade. Tradução de Marco Aulélio Nogueira. 10. ed. São Paulo: Paz e Terra, 2003.

CADEMARTORI, Sérgio. Estado de direito e legitimidade - Uma abordagem garantista. 2. ed. Campinas, SP: Millennium Editora, 2006.

CADEMARTORI, Daniela Mesquita Leutchuk de;

CADEMARTORI, Sergio. A relação entre Estado de direito e 
democracia no pensamento de Bobbio e Ferrajoli. In: Seqüência. N. 53 Curso de Pós-graduação em Direito - UFSC, dez. 2006. p. 145-162.

.O corpus iuris civilis e a mudança no fundamento de validade do direito. In: Novos Estudos Jurídicos. NEJ - Vol. 11 - n. 1. Janjun, 2006, p. 75-101.

CANOTILHO, J. J. Gomes. "Brancosos” e Interconstitucionalidade. Itinerários dos discursos sobre a historicidade constitucional. Coimbra: Almedina, 2006.

CARBONELL, Miguel (ed). Neoconstitucionalismo(s). 2. ed. Madrid: Editorial Trotta, 2005.

. Teoría del neoconstitucionalismo. Ensayos escogidos. Madrid: Editorial Trotta, 2007.

FERRAJOLI, Luigi. A soberania no mundo de hoje. Nascimento e crise do Estado Nacional. Tradução de Carlo Coccioli; Márcio Lauria Filho. São Paulo: Martins Fontes, 2002.

.Derechos y garantías. La ley del más débil. Traducción de Perfecto Andrés Ibáñez. 5. ed. Madrid: Editorial Trotta, 2006.

- Derecho y razón. Teoria del garantismo penal. Traducción de Perfecto Andrés Ibañes, Alfonso Ruiz Miguel, Juan Carlos Bayón Mohino, Juan Terradillos Basoco, Rocio Cantarero Bandrés. 4. ed. Madrid: Editorial Trotta, 2000.

Epistemologia Jurídica y garantismo. México: Fontamara, 2006.

Pasado y futuro del Estado de derecho. In: CARBONELL, 
56 | InterAção

M. (ed). Neoconstitucionalismo(s). 2a ed. Madrid: Editorial Trotta, 2005. p. 13-29.

Principia iuris. Teoria del diritto e della democrazia. Teoria della democracia. Roma: Editori Laterza, 2007.

HART, Herbert L. A. O conceito de direito. Tradução de A. Ribeiro Mendes. 5. ed. Lisboa: Fundação Calouste Gulbenkian, 2007.

KELSEN, Hans. Teoria pura do direito. Tradução João Baptista Machado. 6. ed. São Paulo: Martins Fontes, 1998.

STRECK, Lenio. Verdade e Consenso. Constituição, Hermenêutica e Teorias Discursivas. Da possibilidade à necessidade de respostas corretas em direito. 3.ed. Rio de Janeiro: Editora Lumen Juris, 2009.

VENTURA, Deisy. As assimetrias entre o Mercosul e a União Européia: os desafios de uma associação inter-regional. Barueri, SP: Manole, 2003.

Hiatos da transnacionalização na nova gramática do direito em rede: um esboço da conjugação entre estatalismo e cosmopolitismo. In: STRECK, Lenio Luiz; BOLZAN DE MORAIS, Jose Luis [et al] (Org.). Constituição, Sistemas Sociais e Hermenêutica. Porto Alegre: Livraria do Advogado; São Leopoldo: UNISINOS, 2008. p. 223-240.

Uma caixa de ressonância de eventos no plano global. In:

Prisma Jur., São Paulo, v. 8, n. 1, jan./jun., 2009.

ZAGREBELSKY, Gustavo. El derecho dúctil. Ley, derechos, justicia. Traducción de Marina Gascón. 7. ed. Madrid: Editorial Trotta, 2007. 